The Effectiveness of a Leg-Kicking Training Program on Performance and

Physiological Measures of Competitive Swimmers

by

Maria Konstantaki and Edward M. Winter

Reprinted from

International Journal of

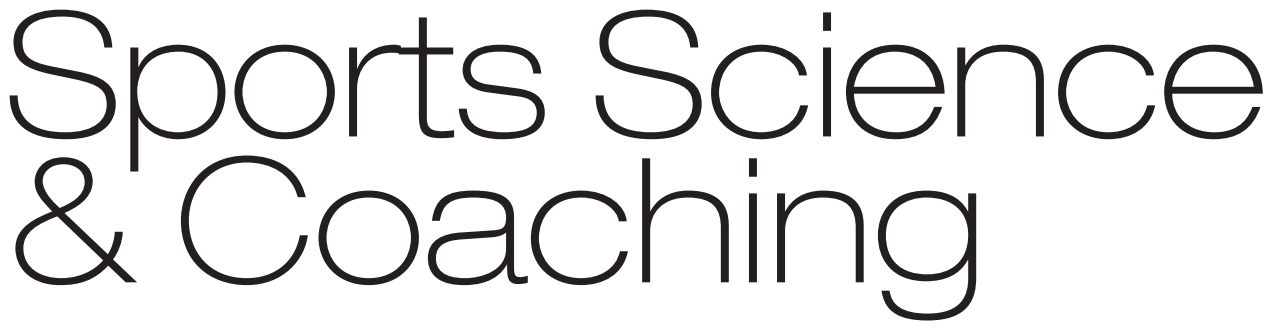

Volume 2 - Number 1 - 2007 


\title{
The Effectiveness of a Leg-Kicking Training Program on Performance and Physiological Measures of Competitive Swimmers
}

\author{
Maria Konstantaki ${ }^{\mathbf{1}}$ and Edward M. Winter ${ }^{\mathbf{2}}$ \\ ${ }^{1}$ School of Sport, Leisure and Travel, Buckinghamshire Chilterns University \\ College, Wellesbourne Campus, Kingshill Road, High Wycombe, \\ Buckinghamshire HP13 5BB, UK \\ E-mail: maria.konstantaki@bcuc.ac.uk \\ ${ }^{2}$ Centre for Sport and Exercise Science, Sheffield Hallam University
}

\begin{abstract}
This study investigated the adaptations in leg muscle metabolism of swimmers following a six-week, leg-kicking swimming training program. Fifteen male competitive swimmers were randomly assigned to an experimental group $(E ; n=8)$ and a control group $(C ; n=7)$. E swimmers performed normal leg-kicking training three times per week, whereas $\mathrm{C}$ swimmers performed reduced leg-kicking training (20\% and $4 \%$ of weekly training distance, respectively). Before and after the training program, all swimmers performed a $200 \mathrm{~m}$ leg-kicking and a $400 \mathrm{~m}$ full-stroke freestyle time trial and a dry-land exercise test during which peak oxygen uptake, oxygen uptake at $60 \mathrm{~W}$ and exercise intensity at ventilatory threshold were measured. After training, there were improvements in leg-kicking time in 200 $\mathrm{m}(\mathrm{s} ;-6.0 \pm 2.0 \%, \mathrm{p}=0.044)$, oxygen uptake at 60 Watts (L· $\mathrm{min}^{-1} ;-20.4 \pm$ $3.0 \%, p=0.035$ ) and exercise intensity at ventilatory threshold (Watts; +28.0 $\pm 5.0 \%, p=0.023$ ) in E swimmers, whereas time in $400 \mathrm{~m}$ and peak oxygen uptake remained unchanged ( $p>0.05$ ). There were no changes in any of the measures for $C$ swimmers $(P>0.05)$. These results suggest that normal leg-kicking swimming training positively affects the conditioning of the legs, but does not improve aerobic power during the dry-land, leg-kicking exercise test or middle-distance, full-stroke, swimming performance.
\end{abstract}

Key words: Dry-Land, Leg-Kicking Exercise Test, Movement Economy, Oxygen Uptake, Swimming Performance, Ventilatory Threshold

\section{INTRODUCTION}

Research into metabolic adaptations in physiological measures of swimmers following leg swimming training has been limited. Previous studies have postulated that forward propulsion in freestyle swimming is predominantly accomplished through the arm stroke

Reviewers: $\quad$ Raúl Arellano (Granada University, Spain)

Kari Keskinen (University of Jyväskylä, Finland) 
with minimal contribution from the leg kick [1-6]. Similarly, other studies have stated that the leg kick is the most inefficient action of freestyle swimming $[7,8]$ and its main functions are to stabilise the trunk [9] and keep the body in a streamlined position during swimming to reduce drag [10]. Conversely, in a recent study that used analysis of motion, it was shown that the legs actually improve the propulsive action of the arms thereby enhancing the generated propulsive force of the whole body [11].

Investigations into changes in aerobic power of swimmers following swimming training have examined the specificity of swimming training on aerobic power [12], the changes in aerobic power due to swimming training in untrained female swimmers [13], due to training of reduced volume [14] and due to swimming training of different duration [15]. These studies focussed on the effects of swimming training on aerobic power during full-stroke swimming. Other studies have assessed the effects of arm swimming training on swimming performance and showed that increasing arm power through swimming training improves full-stroke swimming performance [16-19]. However, the effects of leg swimming training on full-stroke freestyle swimming performance have not been investigated.

Aerobic power of swimmers has been previously assessed during swimming and during dry-land leg-kicking exercise. Such studies have suggested that oxygen uptake during legsonly swimming is higher than during arms-only swimming [20] and that peak oxygen uptake is $20 \%$ higher during dry-land leg-kicking than during dry-land arm-pulling in competitive swimmers $[21,22]$. The higher oxygen uptake responses during legs-only swimming and dry-land leg-kicking exercise compared to arms-only swimming and dry-land arm-pulling exercise are in agreement with previous studies that have investigated arm versus leg exercise in response to arm or leg training [23]. However, the changes in aerobic power during a dry-land, leg-kicking exercise test of swimmers that occur following leg swimming training have not been investigated.

Movement economy has been investigated previously using leg cycling training [23, 24]. Even though these studies provided insight into physiological adaptations that occur in the legs of cyclists and runners due to leg training, they cannot have any direct implications for the training of swimmers. The changes in swimming economy following reduced swimming training were investigated in one study [13]. However, this study investigated the effects of detraining on whole body swimming economy. To date, there have not been any published investigations of the changes in movement economy during a dry-land, leg-kicking exercise test of swimmers due to leg swimming training.

The ventilatory threshold (VT) has been used as a non-invasive marker of the anaerobic threshold [25] in attempts to explain running [26] and cycling performance [27]. Similarly, training studies that have assessed the responses to leg exercise have shown a reduction in the $\dot{\mathrm{VE}} / \mathrm{VO}_{2}$ relationship at given power outputs following leg cycling training $[28,29]$. However, none of these studies used leg swimming training or swimmers. It is possible to identify a breakpoint in the $\mathrm{VE} / \mathrm{VO}_{2}$ relationship during swimming using increasing speeds in a swimming flume [30], but there have not been any published investigations of the adaptations in the ventilatory threshold due to leg swimming training.

Assessments of aerobic power and movement economy during a dry-land, leg-kicking exercise test, and swimming performance following legs-only swimming training might provide insight into the magnitude of metabolic adaptations that occur in the legs of swimmers following normal leg swimming training. Furthermore, assessments of legs-only and full-stroke swimming performance following normal leg swimming training might indicate the amount of leg-kicking swimming training required to induce improvements in full-stroke freestyle swimming performance. These findings could then assist coaches in the 
design of more effective swimming training programmes. Therefore, the purpose of this study was first, to investigate the changes that occur in the aerobic capabilities and movement economy of the legs following normal freestyle leg-kicking swimming training and second, to explore whether such changes bring about improvements in freestyle swimming performance.

\section{METHODS}

\section{PARTICIPANTS}

This study was approved by the North Bedfordshire Ethics Committee. Fifteen male competitive swimmers (mean $\pm \mathrm{SD}$; age: $16.0 \pm 5.0$ years, stature: $175.0 \pm 5.0 \mathrm{~cm}$, body mass: $72.0 \pm 8.0 \mathrm{~kg}$ ), who were randomly assigned to one of two groups: a) an experimental group $(\mathrm{E}, \mathrm{n}=8)$ and $\mathrm{b})$ a control group $(\mathrm{C}, \mathrm{n}=7)$, provided informed consent and participated in the study. There were no differences in anthropometric characteristics between the experimental and control group $(\mathrm{p}>0.05)$. All participants were competitive swimmers who engaged in training for 1.5 hours at least five times per week for a period of four months preceding the training study. Their competitive experience ranged from four to eight years and they were all members of the same swimming club. The mean $\pm \mathrm{SD}$ for freestyle swimming performance at $400 \mathrm{~m}$ before the training begun was $309 \pm 25 \mathrm{~s}$ in $\mathrm{E}$ swimmers and $313 \pm 20 \mathrm{~s}$ in $\mathrm{C}$ swimmers. Training distance was recorded for a period of two months preceding the study and averaged $20,000 \pm 2,500 \mathrm{~m}$ per week. The training study took place in the preparatory phase of the swimmers' annual training cycle (October November). The amount of legs-only swimming training the swimmers performed before the training programme was recorded for a month prior to the study and averaged $4 \pm 2 \%$ of the weekly training distance (i.e., $800 \pm 400 \mathrm{~m}$ per week). However, it is important to emphasise that this type of legs-only swimming training included swimming exercises for all four strokes (depending on the swimmer's individual stroke) and not just freestyle swimming exercises.

\section{THE FREESTYLE LEG-KICKING SWIMMING TRAINING PROGRAM}

The freestyle leg-kicking swimming training program was performed over six weeks and at a frequency of three times per week on alternate days by all swimmers in the experimental group [E]. During these sessions, E swimmers performed normal kicking training (i.e., 20\% of the weekly training distance), whereas $\mathrm{C}$ swimmers performed standard training. Standard training included approximately $4 \%$ of leg-kicking training. The total training volume was equal in both groups. E swimmers performed approximately 4,000 m leg-kicking training per week in all three leg-kicking training sessions (i.e., $20 \%$ of 20,000 m). In each leg-kicking training session, it was estimated that E swimmers covered approximately $1333 \mathrm{~m}$ using legkicking exercises. The leg-kicking exercises were arranged in sets consisting of moderate intensity leg-kicking (to elicit heart rate responses between $130-150$ beats $\mathrm{min}^{-1}$ ) and moderate to high intensity leg-kicking $\left(150-170\right.$ beats $\left.\cdot \mathrm{min}^{-1}\right)$ with some sprint work $(>170$ beats $\cdot \min ^{-1}$ ) being performed at the end of each leg-kicking session. The training sets included repeated distances of $66.6 \mathrm{~m}, 133.3 \mathrm{~m}$ and $166.6 \mathrm{~m}$. Resting intervals ranged between 15-25 s depending on the distance of the exercise (exercise to rest ratio of 2:1) with 1 -minute rest between sets. The swimming training was carried out in a $33.33 \mathrm{~m}$ swimming pool. For the leg-kicking training E swimmers swam in a different lane to $\mathrm{C}$ swimmers. The freestyle leg-kicking training was performed in the beginning of each assigned training session immediately after the warm-up. Freestyle leg-kicking exercises were performed with fins only, with fins and kickboard, with kickboard only and without kicking aids. The 
percentage of leg-kicking work performed was equally divided between kicking variants (i.e., $5 \%$ with fins only, $5 \%$ with fins and kickboard, $5 \%$ with kickboard only and $5 \%$ without kicking aids).

\section{THE SWIMMING TIME TRIALS}

All swimmers (E and $\mathrm{C}$ ) performed two time trials before and after the six-week training program. The time trials comprised $200 \mathrm{~m}$ freestyle leg-kicking $\left(200_{\text {legs }}\right)$ and $400 \mathrm{~m}$ fullstroke freestyle swimming $\left(400_{\text {full }}\right)$ and were performed during the same week, two days apart (to minimise any effects of residual fatigue on performance) and in a randomised order (to eliminate any learning effects) before and after the training program. Both time trials were performed at maximum effort and the time taken to cover the set distances was recorded for every swimmer. For the $200_{\text {legs }}$ time trial, swimmers were asked to cover six lengths of the swimming pool using freestyle leg-kicking with a kickboard. For the $400_{\text {full }}$ time trial, swimmers were instructed to swim twelve lengths as fast as possible using standard freestyle swimming. All swimmers performed a familiarisation session with the time trials on two separate occasions a week prior to the actual time trials taking place. Both time trials were performed in the beginning of the training session immediately after the warm up. The swimmers started both time trials by pushing off the pool wall and were allowed to tumble turn in the full-stroke trial. Both time trials were performed in a $33.3 \mathrm{~m}$ swimming pool.

\section{THE DRY-LAND LEG-KICKING EXERCISE TEST}

The dry-land leg-kicking exercise test involved incremental leg-kicking exercise to exhaustion on a specially designed leg-kicking ergometer. The leg-kicking ergometer comprised a leg-kicking machine that was connected to the resistance unit of an interfaced swim bench to allow assessment of power output during leg-kicking exercise (Plate 1). The operation and calibration of this ergometer have been described previously [31]. All swimmers attended a familiarisation session in the laboratory where they were allowed to exercise on the leg-kicking ergometer for a period of approximately 5 minutes. Swimmers were instructed to simulate the freestyle leg-kicking action by kicking downwards with alternating legs. Swimmers adopted a prone position on a swim bench and placed their feet in the stirrups of the leg-kicking ergometer. The distance between the swim bench and the leg-kicking ergometer was adjusted according to the swimmer's stature to allow the swimmers to flex their knees to $45^{\circ}$ during leg kicking. Immediately prior to and after the swimming training program, all swimmers performed an incremental leg-kicking exercise test to volitional exhaustion on the leg-kicking ergometer. The leg-kicking test was performed in the same week as the swimming time trials and after one full day of rest following the time trials. Maximal kick velocity (MKV) was set constant at $2.66 \mathrm{~m} \cdot \mathrm{s}^{-1}$ to allow optimal kicking rate at lower and higher resistance settings [32]. Swimmers were allowed a freely chosen warm up before they started the leg-kicking exercise test. To allow collection of expired gases and determination of oxygen uptake at $60 \mathrm{~W}$ and at exhaustion, swimmers were fitted with a mouthpiece connected to on-line gas analysis equipment. Swimmers began leg-kicking at different intensities of exercise depending on age. Male swimmers over 18 years began leg-kicking at $30 \mathrm{~W}$, whereas younger males (16-17 years) began leg-kicking at $20 \mathrm{~W}$. The intensity of exercise was dictated by a computer program [21] and was set to increase by $7.5 \mathrm{~W} \cdot \mathrm{min}^{-1}$ (Slow Ramp Test). The leg-kicking exercise test was designed to elicit maximum responses in approximately 15 minutes and so minimise local muscle fatigue. The test ended when swimmers failed to maintain exercise intensity within $\pm 20 \mathrm{~W}$ of the target power output as dictated by the computer program. 


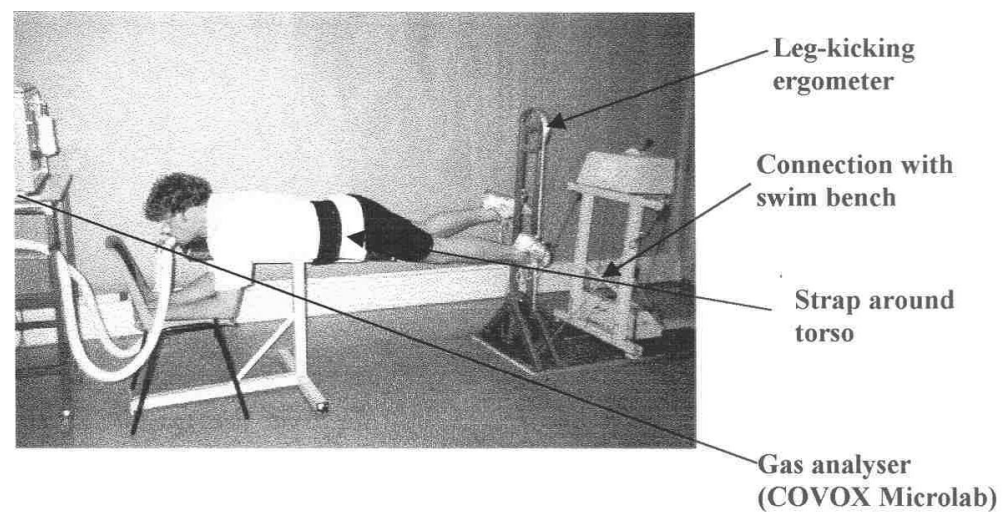

Plate 1. The Leg-Kicking Exercise Test Showing the Leg-Kicking Ergometer, the Swim Bench Transducer Unit Connection and the On-Line Gas Analysis System.

\section{GAS ANALYSIS}

Expired gases were analysed for their oxygen and carbon dioxide output using on-line gas analysis equipment (COVOX Microlab, Exeter, UK). This equipment comprised oxygen and infra-red carbon dioxide analysers and a pneumotachograph (Servomex Ltd., Sussex, UK). Calibration of the gas analyser was performed immediately prior to and after every testing session using nitrogen and a gas of known concentration $\left(4.95 \% \mathrm{CO}_{2}, 15 \% \mathrm{O}_{2}+21.5 \% \mathrm{O}_{2}\right.$; BOC Gases Ltd., Surrey, UK). The reason for using two calibration gases for $\mathrm{O}_{2}$ was to span the operating range. The aim of this method was to perform calibration above and below the expected $\mathrm{O}_{2}$ values. Expired gases were mixed in a 3-litre mixing chamber and were sampled at 15 -s intervals. Oxygen uptake values were recorded every $30 \mathrm{~s}$ (as the mean of two $15 \mathrm{~s}$ values). During the leg-kicking exercise test, submaximal oxygen uptake was recorded at the end of the minute while exercising at $60 \mathrm{~W}\left(\dot{\mathrm{VO}}_{2}-60\right)$ and peak oxygen uptake $\left(\mathrm{VO}_{2 \text { peak }}\right)$ was recorded at exhaustion. To ascertain the reproducibility of gas analysis readings, six participants performed the leg-kicking test on two separate occasions spaced two days apart. Pearson's moment product correlation was performed on the two sets of data and the calculated R-value was 0.96 (mean \pm SEM: $2.93 \pm 0.65$ ).

\section{DETERMINATION OF VENTILATORY THRESHOLD (VT)}

The method used for determination of VT was based on that suggested by Fukuba et al. [33]. The VT was taken to be the point at which there was a sudden systematic increase in the ventilatory equivalent for $\mathrm{O}_{2}\left(\dot{\mathrm{VE}} / \mathrm{V}_{2}\right)$ and was determined during incremental leg-kicking exercise before and after the six-week legs-only swimming training program. The values for $\mathrm{VE} / \mathrm{VO}_{2}$ were plotted against exercise intensity (W). To determine the exercise intensity that corresponded to the VT $\left(\mathrm{VT}_{\mathrm{W}}\right)$, the graphical technique proposed by Swaine [34] was employed. This technique involved fitting two straight lines on the $\mathrm{VE} / \mathrm{VO}_{2}$ data (one before and one after the VT breakpoint) indicating a 'V-slope'. The point at which these two lines intersected was taken as the exact point of VT. The exercise intensity that coincided with the VT was interpolated from this point [35]. An example of this technique is shown in Figure 1. The reproducibility of $\mathrm{VT}_{\mathrm{W}}$ was assessed using the gas analysis data of six swimmers (as described in the previous section) and was shown to be 0.92 . 


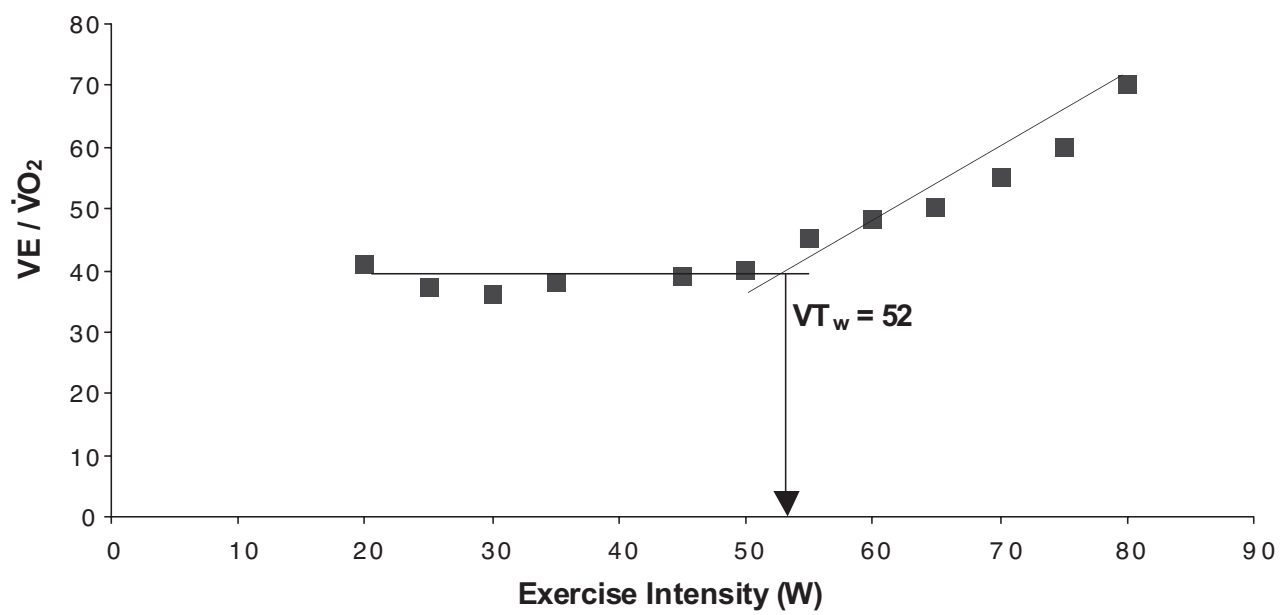

Figure 1. Determination of Exercise Intensity at Ventilatory Threshold $\left(\mathrm{VT}_{\mathrm{W}}\right)$ for One Participant.

\section{STATISTICAL ANALYSIS}

Following assessments of normality of data, homogeneity of variance and sphericity, as appropriate, a mixed-design factorial Analysis of Variance (ANOVA) was employed to assess the differences in $200 \mathrm{~m}$ leg-kicking $\left(200_{\text {legs }}\right)$ and $400 \mathrm{~m}$ full-stroke $\left(400_{\text {full }}\right)$ freestyle swimming performance and submaximal oxygen uptake at $60 \mathrm{~W}\left(\mathrm{VO}_{2}-60\right)$, peak oxygen uptake $\left(\mathrm{VO}_{2 \text { peak }}\right)$ and exercise intensity at ventilatory threshold $\left(\mathrm{VT}_{\mathrm{W}}\right)$ between $\mathrm{E}$ and $\mathrm{C}$ swimmers. Repeated measures ANOVA was employed to assess the differences between the pre- and post-training values for $200_{\text {legs, }} 400_{\text {full, }} \dot{\mathrm{VO}}_{2}-60, \dot{\mathrm{VO}}_{2 \text { peak }}$ and $\mathrm{VT}_{\mathrm{W}}$ in $\mathrm{E}$ and $\mathrm{C}$ swimmers. Significance levels were set at $\mathrm{p} \leq 0.05$. Values are reported as mean and standard deviation (SD).

Table 1. Dry-Land Leg-Kicking Exercise Values for Peak Oxygen Uptake $\left(\mathrm{VO}_{2 \text { peak }}\right)$ and Time in the $400 \mathrm{~m}$ Full-Stroke Freestyle Swimming Time Trial $\left(400_{\text {full }}\right)$ Before and After the Six-Week Freestyle Leg-Kicking Swimming Training Program in Experimental $(E ; n=8)$ and Control Group $(C ; n=7)$ Swimmers. Values are mean \pm SD.

\begin{tabular}{lllll} 
& \multicolumn{2}{l}{ Experimental group } & \multicolumn{2}{l}{ Control Group } \\
\hline & Pre-training & Post-training & Pre-training & Post-training \\
\hline $\mathrm{VO}{ }_{2 \text { peak }}\left(\mathrm{L} \cdot \mathrm{min}^{-1}\right)$ & $2.61 \pm 0.40$ & $2.57 \pm 0.37$ & $2.63 \pm 0.32$ & $2.61 \pm 0.35$ \\
\hline $400_{\text {full }}(\mathrm{s})$ & $309 \pm 25.0$ & $307 \pm 20.0$ & $313 \pm 19.0$ & $311 \pm 21.0$ \\
\hline
\end{tabular}

\section{RESULTS}

\section{PRE-TRAINING RESULTS}

Before the training program, no differences were identified between the $\mathrm{E}$ and $\mathrm{C}$ swimmers in the swimming time trials of $200_{\text {legs }}(p=0.054)$ and $400_{\text {full }}(p=0.081)$ and the dry-land leg-kicking exercise measurements of $\mathrm{VO}_{2 \text { peak }}(\mathrm{p}=0.062), \mathrm{VO}_{2}-60(\mathrm{p}=0.053)$ and $\mathrm{VT}_{\mathrm{W}}(\mathrm{p}$ $=0.072$ ). 


\section{POST-TRAINING INTRA-GROUP RESULTS}

After the training program, there were no differences between the pre- and post-training values for $200_{\text {legs, }} 400_{\text {full, }} \mathrm{VO}_{2 \text { peak, }} \mathrm{VO}_{2}-60$ and $\mathrm{VT}_{\mathrm{W}}$ in $\mathrm{C}$ swimmers $(\mathrm{p}>0.05)$, whereas there were no differences for $400_{\text {full }}(\mathrm{p}=0.072)$ and $\mathrm{VO}_{2 \text { peak }}(\mathrm{p}=0.064)$ in E swimmers.

\section{POST-TRAINING INTER-GROUP RESULTS}

Differences were identified between the pre- and post-training values of $200_{\operatorname{legs}}(-6.0 \pm 2 \%$; $\mathrm{p}=0.044), \mathrm{VO}_{2}-60(-20.4 \pm 3 \% ; \mathrm{p}=0.035)$ and $\mathrm{VT}_{\mathrm{W}}(28.0 \pm 5.0 \% ; \mathrm{p}=0.023)$ in $\mathrm{E}$ swimmers. Pre- and post-training values for $400_{\text {full }}$ and $\mathrm{VO}_{2 \text { peak }}$ in $\mathrm{E}$ and $\mathrm{C}$ swimmers are shown in Table 1. Pre- and post-training values for $200_{\text {legs, }} \mathrm{VO}_{2}-60$ and $\mathrm{VT}_{\mathrm{W}}$ are shown in Figures 2, 3 and 4, respectively.

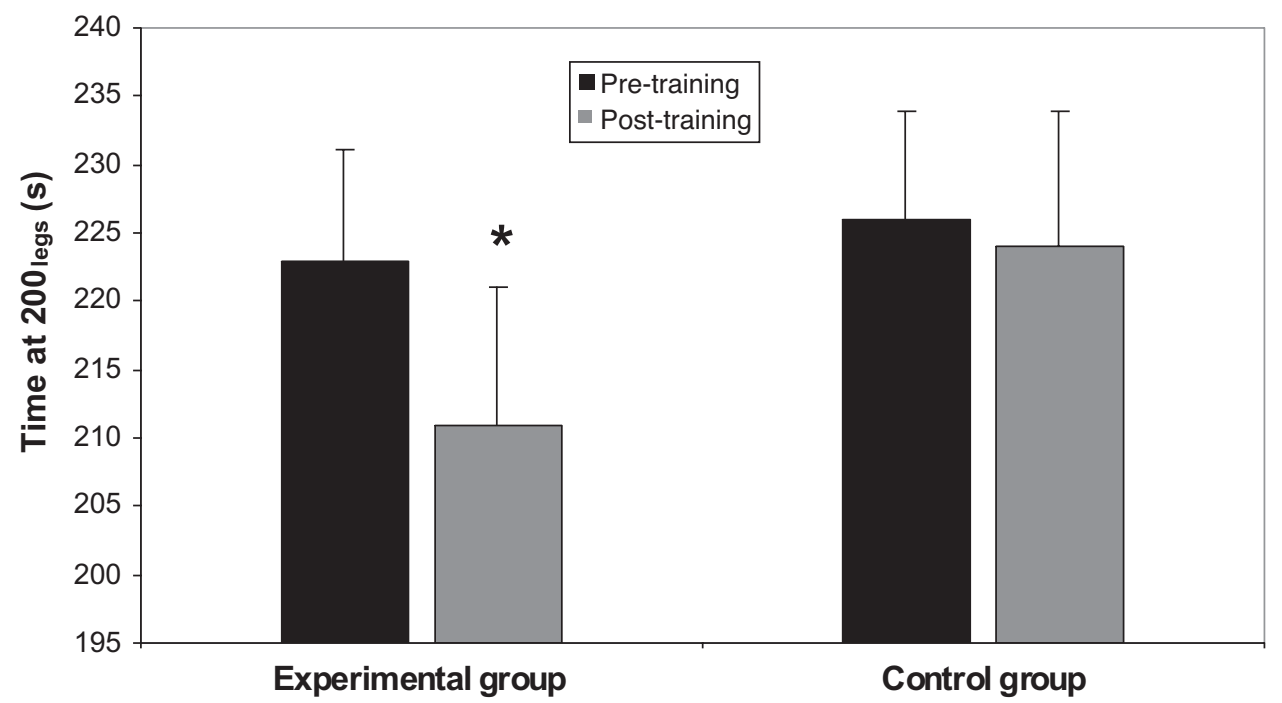

Figure 2. Time at $200 \mathrm{~m}$ Freestyle Leg-Kicking Swimming Trial (s) in the Experimental and Control Group Before and After the Six-Week Freestyle Leg-Kicking Swimming Training Program. Values are mean \pm SD.

* Significant at $P<0.05$.

\section{DISCUSSION}

One of the key findings in this study was that normal leg-kicking swimming training (i.e., 20\% of the weekly training distance) performed three times per week for six weeks improves leg muscle endurance and movement economy, but does not improve aerobic power during the dryland, leg-kicking exercise test or middle-distance swimming performance. These changes were only observed in the experimental group swimmers who undertook the leg-kicking swimming training, whereas there were no changes in leg metabolism of the control group swimmers. Previous studies that have used leg cycling [23, 24] and triathlon training [36] have shown similar training effects where cardiovascular, metabolic and neuromuscular adaptations occurred in the trained segments. In swimming, there have not been any published investigations of the adaptations that occur in leg muscle metabolism of swimmers following leg swimming training with which to compare our data. However, it appears that this type of leg swimming training is sufficient to elicit adaptations in leg muscle metabolism of competitive swimmers. 
The improvements in leg muscle endurance following leg-kicking swimming training were reflected by a decrease in $200 \mathrm{~m}$ leg-kicking swimming times. However, there are no published investigations that have assessed the effects of leg-kicking swimming training on leg muscle endurance in swimmers. Movement economy also improved following the legkicking swimming training and this was reflected by a decrease in oxygen uptake at $60 \mathrm{~W}$ during the dry-land leg-kicking exercise test. Even though the swimmers did not perform leg-kicking training on the dry-land ergometer, the marked reduction in submaximal oxygen uptake at $60 \mathrm{~W}(-20.4 \pm 3.0 \%)$ that was observed in the experimental group following legkicking swimming training suggests that dry-land ergometry can successfully engage the muscle groups activated during freestyle leg-kicking. This finding reinforces previous findings where changes in dry-land arm-pulling economy were demonstrated following swimming training $[22,32]$.

The freestyle leg-kicking swimming training used in this study did not improve aerobic power during the dry-land, leg-kicking exercise test in either the experimental or the control group swimmers. Improvements in leg aerobic power have been observed following cycling training $[37,38]$. However, these studies used untrained participants and thus the changes that were noted in aerobic power measured following cycling training could be attributed to the participants' low initial state of training. Swimming studies that have assessed the effects of arm swimming training on aerobic power measured during full-stroke swimming noted improvements following training $[13,15]$, but these studies also used untrained participants. In our study we used trained swimmers who might have reached their maximum aerobic potential due to competitive swimming training and thus required a higher percentage of legsonly swimming training $(<20 \%)$ or training of longer duration (than six weeks) to bring about significant improvements in aerobic power during the dry-land, leg-kicking exercise test.

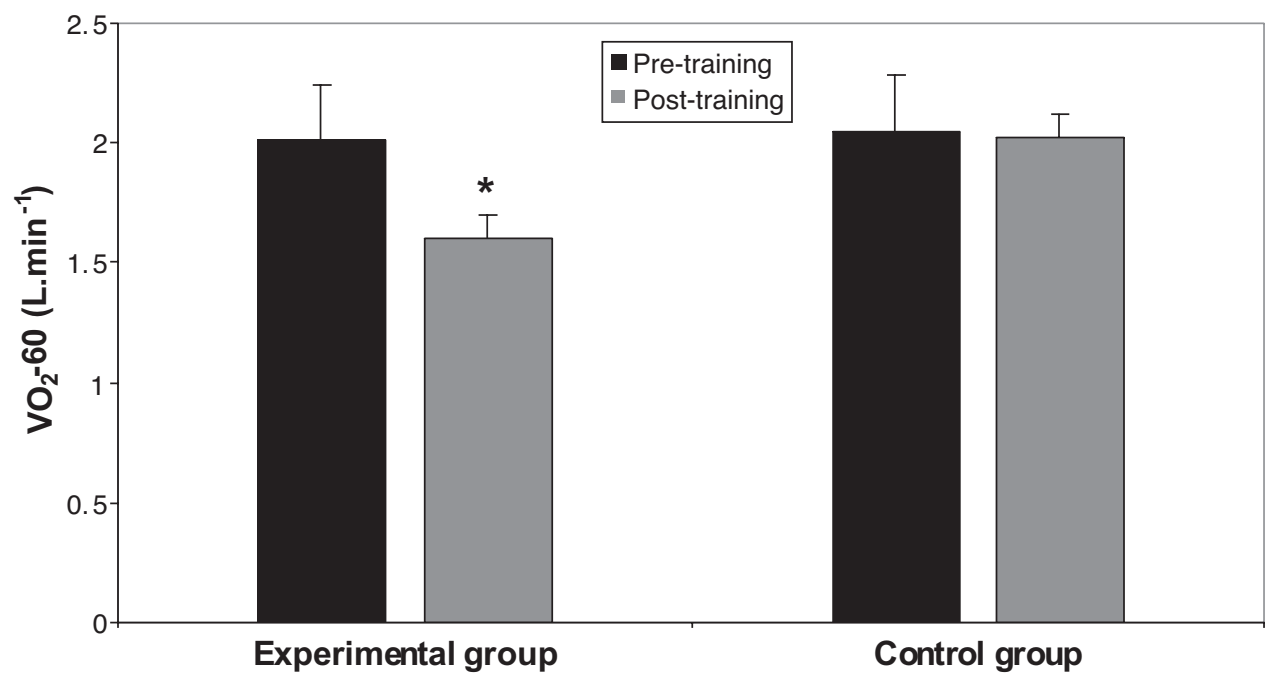

Figure 3. Oxygen Uptake at $60 \mathrm{~W}\left(\dot{\mathrm{VO}}_{2}-60 ; \mathrm{L}^{-\mathrm{min}^{-1}}\right)$ in the Experimental and Control Groups Before and After the Six-Week Freestyle Leg-Kicking Swimming Training Program. Values are mean \pm SD.

* Significant at $\mathrm{P}<0.05$. 
Another notable result in this study was the increase in exercise intensity at which ventilatory threshold was reached during dry-land, leg-kicking exercise following legkicking swimming training $(+28.0 \pm 5.0 \%)$. Again, this improvement only occurred in the experimental group swimmers. This finding compares favourably with those of previous studies that have used running [39] and leg cycling training [28, 29] and found similar improvements in the power output at which the ventilatory threshold was reached following training. There have not been any training studies that have investigated the changes in $\mathrm{VT}_{\mathrm{W}}$ following leg-kicking swimming training with which to compare our data. However, one study that used swimmers and investigated the $\mathrm{VT}_{\mathrm{W}}$ during arm-pulling exercise showed that VT was achieved at $100 \pm 20 \mathrm{~W}$ [34]. In this study, $\mathrm{VT}_{\mathrm{W}}$ during leg-kicking exercise was achieved at $62 \pm 8 \mathrm{~W}$ and $75 \pm 6 \mathrm{~W}$ for the control and experimental group, respectively (both values are post-training). The lower exercise intensities at which VT was achieved in this study suggest that the $\mathrm{VT}_{\mathrm{W}}$ of competitive swimmers during dry-land leg-kicking exercise is considerably lower compared to $\mathrm{VT}_{\mathrm{W}}$ during arm-pulling exercise. These differences lend support to the notion that arm pulling is a more efficient action compared to leg kicking during freestyle swimming [7, 8]. However, it might also be the case that leg-kicking swimming training had been de-emphasised in favour of whole-body or arm-pulling swimming training.

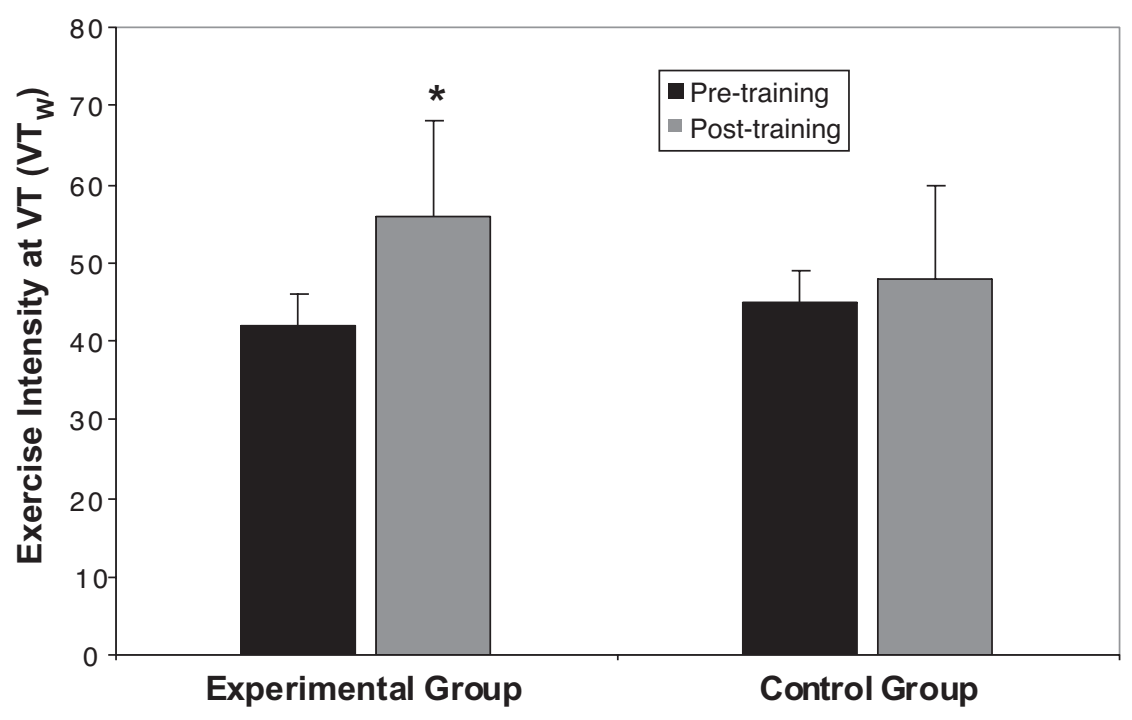

Figure 4. Exercise Intensity at Ventilatory Threshold $\left(V T_{W}\right)$ in the Experimental and Control Groups Before and After the Six-Week Freestyle Leg-Kicking Swimming Training Program. Values are mean \pm SD.

* Significant at $P<0.05$.

There were no improvements in $400 \mathrm{~m}$ freestyle swimming performance following freestyle leg-kicking swimming training in either the experimental or the control groups in this study. Previous studies have shown that increasing arm power through swimming training improves full-stroke sprint swimming performance [16-19]. However, there have not been any published investigations of the effects of leg-kicking swimming training on 
middle-distance swimming performance. Furthermore, the type of training used in this study was designed to increase leg endurance rather than leg power; hence, the marked changes in $200 \mathrm{~m}$ legs-only swimming time, dry-land movement economy and dry-land exercise intensity at ventilatory threshold. It would be interesting to explore whether a different type of legs-only training (designed to improve leg power through swimming training) might have an effect in improving full-stroke middle-distance swimming performance.

\section{CONCLUSION AND RECOMMENDATIONS}

The findings of this study demonstrate that six weeks of normal freestyle leg-kicking swimming training (20\% of the weekly training distance) can enhance movement economy and can improve leg endurance. It appears that normal leg-kicking training is effective in inducing training adaptations in the localised metabolism of the legs of competitive swimmers. Such findings indicate that normal leg-kicking training should form an essential part of the training regimen, as it improves leg conditioning. Swimming coaches could use this knowledge to design swimming training programs so that it incorporates the normal amount of leg-kicking training. In addition, these findings could be of interest to sports scientists who wish to conduct in-depth investigations of the effects of leg swimming training on leg muscle metabolism of swimmers. Moreover, the findings of this study indicate that normal freestyle leg-kicking swimming training does not affect full-stroke middle-distance swimming performance. It would be interesting to ascertain whether a combined arm-pulling and leg-kicking swimming training program set at $20 \%$ of the weekly training distance for each component would have an effect on middle-distance swimming performance.

Dry-land leg-kicking exercise seems to successfully engage the musculature involved in freestyle leg-kicking and can be used alongside water-based assessments to monitor the improvements that occur in leg metabolism of swimmers in response to leg-kicking swimming training. This type of dry-land ergometry could be used in conjunction with water-based training as an alternative form of land-based training to supplement or substitute traditional weight training. Coaches could use these methods with their swimmers to investigate their effectiveness on improving swimming performance.

\section{ACKNOLWEDGEMENTS}

The authors wish to acknowledge the collaboration of Mr. Charlie Wilson, former Olympic coach and coach of the Bedford Modernians Swimming Club and all the swimmers who participated in the training program, the time trials and laboratory assessments.

\section{REFERENCES}

1. Adrian, M.J., Singh, M. and Karpovich, P.V., Energy Cost of Leg Kick, Arm Stroke and Whole Stroke, Journal of Applied Physiology, 1966, 21, 1763-1766.

2. Alley, L.E., An Analysis of Water Resistance and Propulsion in Swimming the Crawl Stroke, Research Quarterly, 1952, 23, 253-269.

3. Hollander, A.P., de Groot, G., van Ingen Schenau, G.J., Kahman, R. and Toussaint, H.M., Contribution of the Legs to Propulsion in Front Crawl Swimming, in: Ungerechts, B.E., Wilke, K. and Reischle, K., eds., Swimming Science V, Human Kinetics, Champaign, IL, 1988, 39-43.

4. Magel, J.R., Propelling Force Measured during Tethered Swimming in the Four Competitive Swimming Styles, Research Quarterly, 1970, 41, 68-74.

5. Ohkuwa, T. and Itoh H., Blood Lactate, Glycerol and Catecholamine in Arm Strokes, Leg Kicks and Whole Crawl Strokes, Journal of Sports Medicine and Physical Fitness, 1992, 32, 32-38. 
6. Toussaint, H.M. and Beek, P.J., Biomechanics of Competitive Front Crawl Swimming, Sports Medicine, 1992, 13, 384-387.

7. Bucher, W., The Influence of the Leg Kick and the Arm Stroke on the Total Speed during the Crawl Stroke, in: Clarys, J.P., Lewillie, L., eds., Swimming II, University Park Press, Baltimore, MD, 1974, 180-187.

8. Karpovich, P.V., Analysis of the Propelling Force in the Crawl Stroke, Research Quarterly, 1955, 6, 49-58.

9. Laurence, L., The Importance of the Free Style Leg Kick, International Swimmer, 1969, 5, 11-12.

10. Councilman, J.E., Doctor Councilman on Swimming, Pelham, London, 1977.

11. Deschodt, V.J., Arsac, L.M. and Rouard A.H., Relative Contribution of Arms and Legs in Humans to Propulsion in 25m Sprint Front Crawl Swimming, European Journal of Applied Physiology and Occupational Physiology, 1999, 80, 192-199.

12. Magel, J.R., Foglia, G., McArdle, W.D., Gutin, B., Pechar, G. and Katch, F.I., Specificity of Swim Training on Maximum Oxygen Uptake, Journal of Applied Physiology, 1975, 3, 151-155.

13. D'Acquisto, L.J., Dursthoff, P., Spry, S., Letner, C., Badger, S. and Troup, J.P., Physiological Adaptations to Swim Training in Untrained Female Swimmers, in: MacLaren, D., Reilly, T. and Lees, A., eds., Biomechanics and Medicine in Swimming, Swimming Science VI, E. and F.N. Spon, London, 1992, 207-212.

14. D’Acquisto, L.J., Bone, M., Takahashi, S., Langhans, G., Barzdukas, A.P. and Troup, J.P., Changes in Aerobic Power and Swimming Economy as a Result of Reduced Training Volume, in: MacLaren, D., Reilly, T. and Lees, A., eds., Biomechanics and Medicine in Swimming, Swimming Science (Vol. 6), E. and F.N Spon, London, 1992, 201-206.

15. D’Acquisto, L.J., Barzdukas, A.P., Dursthoff, P., Letner, C. and Troup, J.P., Physiological Adaptations to 60 vs. 20 minutes of Swim Training at $76 \% \dot{\mathrm{VO}}_{2 \max }$, in: MacLaren, D., Reilly, T. and Lees, A., eds., Biomechanics and Medicine in Swimming, Swimming Science (Vol. 6), E. and F.N. Spon, London, 1992, 195199.

16. Charbonier, J.P., Lacour, J.R. and Riffat, J., Experimental Study of the Performance of Competition Swimmers, European Journal of Applied Physiology, 1975, 34, 157-167.

17. Costill, D.L., King, D.S. and Holdren, A., Sprint Speed versus Swimming Power, Swimming Technique, 1983, 20, 20-22.

18. Sharp, R.L., Troup, J.P. and Costill, D.L., Relationship between Power and Sprint Free Style Swimming Performance, Medicine and Science in Sports and Exercise, 1982, 14, 53-56.

19. Toussaint, H.M. and Vervoorn, K., Effects of Specific High Resistance Training in the Water on Competitive Swimmers, International Journal of Sports Medicine, 1990, 11, 228-233.

20. Keskinen, K.L. and Komi P.V., Effect of Leg Action in Stroke Performance in Swimming, in: McLaren, D., Reilly, T. and Lees A., eds., Biomechanics and Medicine in Swimming, Swimming Science VI, E. and F.N. Spon, London, 1992, 251-256.

21. Konstantaki, M. and Swaine I.L., Lactate and Cardiopulmonary Responses to Simulated Arm-Pulling and Leg-Kicking in Collegiate and Recreational Swimmers, International Journal of Sports Medicine, 1999, 20, 118-121.

22. Konstantaki, M., Winter, E.M. and Swaine, I.L., The Effects of Arms- or Legs-Only Training on Indices of Swimming Performance and Dry-Land Endurance in Swimmers, in: Keskinen, K., Komi, P. and Hollander, P., eds., Biomechanics and Medicine in Swimming (Vol. VIII), University of Jyväskylä, Jyväskylä, Finland, 1999, 391-395.

23. Turner, D.L., Hoppeler, H., Claasen, H., Vock, P., Kayser, B., Schena, F. and Ferreti, G., Effects of Endurance Training on Oxidative Capacity and Structural Composition of Human Arm and Leg Muscles, Acta Physiologica Scandinavica, 1997, 161, 459-464.

24. Clausen, J.P., Klausen, K., Rasmussen, B. and Trap-Jensen, J., Effect of Strenuous Arm and Leg Training on Pulmonary Ventilation, Metabolism and Blood pH During Submaximal Exercise, Acta Physiologica Scandinavica, 1971, 82, 8A.

25. Reinhardt, U., Müller, P. and Schmülling, R., Determination of Anaerobic Threshold by the Ventilation Equivalent in Normal Individuals, Respiration, 1979, 38, 36-42. 
26. Farrel, P., Wilmore, J., Coyle, E., Billings, J. and Costill, D.L., Plasma Lactate Accumulation and Distance Running Performance, Medicine and Science in Sport and Exercise, 1979, 11, 338-344

27. Powers, S., Dodd, S. and Garner, R., Precision of Ventilatory and Gas Exchange Alterations as a Predictor of the Anaerobic Threshold, European Journal of Applied Physiology, 1984, 52, 173-177.

28. Clausen, J.P., Larsen, O. and Trap-Jensen, J., Central and Peripheral Circulatory Changes after Training of the Arms or the Legs, American Journal of Applied Physiology, 1973, 225, 685-692.

29. Rasmussen, B., Klausen, K., Clausen, J.P. and Trap-Jensen, J., Pulmonary Ventilation, Blood Gases, and Blood pH after Training of the Arms or the Legs, Journal of Applied Physiology, 1975, 38, 250-256.

30. Holmér, I., Lundin, A. and Erickson, B.O., Maximum Oxygen Uptake during Swimming and Running by Elite Swimmers, Journal of Applied Physiology, 1974, 36, 711-714.

31. Konstantaki, M., Winter E.M. and Swaine, I.L., Peak Oxygen Uptake Responses to Free and Simulated Swimming Using Different Body Segments, Journal of Swimming Research, 2004, 16, 18-24.

32. Swaine, I.L. and Zanker, C., The Reproducibility of Cardiopulmonary Responses to Exercise using a Swim Bench, International Journal of Sports Medicine, 1996, 17, 140-144.

33. Fukuba, Y., Munaka, M., Usui, S. and Sahasara, H., Comparison of Objective Methods for Determining Ventilatory Threshold, Japanese Journal of Physiology, 1988, 38, 133-144.

34. Swaine, I.L., The Relationship between Physiological Variables from a Swim Bench Ramp Test and MiddleDistance Swimming Performance, Journal of Swimming Research, 1994, 10, 41-48.

35. Madsen, O. and Lohberg, M., The Low-Down on Lactates, Swimming Technique, 1987, 3, 21-228.

36. O'Toole, M.L. and Douglas, P.S., Applied Physiology of Triathlon, Sports Medicine, 1995, 19, 251-267.

37. Hardman, A., Williams, C. and Wooton, S., The Influence of Short-Term Endurance Training on Maximum Oxygen Uptake, Submaximum Endurance and the Ability to Perform Brief, Maximal Exercise, Journal of Sports Sciences, 1986, 4, 109-116.

38. Swensen, T.C. and Howley, E.T., Effect of One- and Two-Legged Training on Arm and Two-Leg Maximum Aerobic Power, European Journal of Applied Physiology and Occupational Physiology, 1993, 66, 285-288.

39. Burke, J., Thayer, R. and Belcamino M., Comparison of Effects of Two Interval-Training Programs on Lactate and Ventilatory Thresholds, British Journal of Sports Medicine, 1994, 28, 18-21. 